\title{
Influence of Processing Variables on Some Physico-Chemical Properties and Quality of Manioc Starch-Based Adhesives
}

\author{
Victor D. Olomo \\ Process Concepts and Technologies Limited, Ibadan, Nigeria \\ Email: vickyolomo@yahoo.com
}

How to cite this paper: Olomo, V.D. (2022) Influence of Processing Variables on Some Physico-Chemical Properties and Quality of Manioc Starch-Based Adhesives. Open Journal of Polymer Chemistry, 12, $1-12$.

https://doi.org/10.4236/ojpchem.2022.121001

Received: October 15, 2021

Accepted: February 5, 2022

Published: February 8, 2022

Copyright ( 2022 by author(s) and Scientific Research Publishing Inc. This work is licensed under the Creative Commons Attribution International License (CC BY 4.0).

http://creativecommons.org/licenses/by/4.0/

\begin{abstract}
Bio-degradable cassava starch-based adhesives were produced from chemically gelatinized starch formulations. The varying combinations of process parameters applied include: concentration of gelatinization modifier, mass $\%$ borax/starch, and temperature of reaction mixture. The physico-chemical parameters for characterizing the adhesive samples were viscosity, density, $\mathrm{pH}$ and bonding strength. The effects of the variation of process parameters on the quality of the adhesives were assessed using response surface (central composite) designs with 2 factors, to relate the highest adhesive quality with the optimal combination of process factors. The adhesives produced using $\mathrm{HCl}$ as the gelatinization modifier were of a higher quality than those produced using $\mathrm{NaOH}$ with one of the most important quality assessment parameters which is the bond strength being $22.31 \mathrm{kPa}$ at $0.01 \mathrm{M}$ and $20 \%$ mass borax/starch and $11.60 \mathrm{kPa}$ at $0.01 \mathrm{M}$ and $8 \%$ mass borax/starch for $\mathrm{HCl}$ and $\mathrm{NaOH}$ respectively. The experimental results demonstrated that the optimal temperature for the production of the adhesive was $85^{\circ} \mathrm{C}$.
\end{abstract}

\section{Keywords}

Cassava Starch, Starch Adhesives, Gelatinization, Gelatinization Temperature, Gelatinization Modifier

\section{Introduction}

Cassava (Manihot Esculenta Crantz) is a carbohydrate rich root $(15 \%-33 \%$ starch by proximate analysis) produced principally in the tropical and subtropical regions of Africa, South America and Asia. The utilization of the crop has been largely as food and feeds, and has significantly contributed to the food se- 
curity needs of hundreds of millions in developing countries. Cassava however possesses a vast array of non-food industrial applications, many of which are based on the modification of the native or industrial starches extracted from the root through the wet method. These include its use as thickener, binder, expanding agent, stabilizer and replacement for fat [1].

Starches are made from many different starchy raw materials, such as wheat, barley, maize, rice, white or sweet potatoes, cassava, sago palm and waxy maize. Although they have similar chemical reactions and are usually interchangeable, starches from different sources have different granular structures which affect their physical properties [2]. The use of starch as a raw material in the production of adhesives has several advantages, including: renewability, biodegradability, abundance, cheapness and stability in price [3]. Cassava starch as base for adhesives production has many remarkable characteristics, including high paste viscosity, high paste clarity, and high freeze-thaw stability, which are advantageous to many industries [4].

Due to the peculiar factor endowments of sub-Saharan Africa, and the comparative advantages the region possesses in the cultivation of cassava, it has become very important to explore the non-food industrial utilization potentials and products from the crop within the adhesives industries, most of which are currently imported in various forms into the continent. Harnessing local adhesives production within the sub-region will lead to the development of a basic starch-derived industry able to provide incomes to hundreds of thousands of people participating along the cassava processing value chain through the application of intermediate level technologies to achieve import substitution.

\section{Materials and Methods}

\subsection{Raw Materials and Reagents}

A TMS 30001 species of cassava was used for the study. It was obtained from the International Institute of Tropical Agriculture, Ibadan. Also Sodium Tetraborate (Borax) [Viscosity enhancer], Sodium Hydroxide, and Hydrochloric Acid [Gelatinization Modifiers] were used.

\subsection{Design of Experiment}

Two different sets of experiments were carried out to determine the effects of varying concentrations of reactants and process parameters on the quality of the adhesive produced.

\section{Experiment 1}

In experiment 1, a response surface (central composite) design with 2 factors was used to relate the effects of processing parameters, namely the temperature of heating mantle, and Concentration of Borax on the quality of the adhesive produced for the levels and factors used. A face-centered design (in which $\alpha=1$ ) was used, thereby producing 3 levels. The number of replicates made was two.

Experiment 2 
In experiment 2, a response surface (central composite) design with 2 factors was used to relate the effects of processing parameters, namely Concentration of $\mathrm{NaOH}$ and Concentration of Borax on the quality of the adhesive produced for the level and factors used. A face-centered design (in which $\alpha=1$ ) was also used, thereby producing 3 levels as in the previous experiment. Also, two replicates were made.

\subsection{Production of Cassava Starch}

The cassava roots were peeled and washed, after which they were grated into a pulp. The cassava starch was then washed out of the mix of cassava pulp and clean water, passing through a fine sieve. The starch slurry was then allowed to settle, and the fibre and clean water were decanted. The starch particles recovered were then sun dried on an elevated platform, after which they were milled into fine powder using a hammer mill.

\subsection{Production of Adhesives Using Gelatinization Modifier ( $\mathrm{HCl}$ and $\mathrm{NaOH}$ ) and Viscosity Enhancer (Borax)}

Production of adhesive using $\mathrm{HCl}$ as a gelatinization modifier: $6 \mathrm{~g}$ of dry cassava starch was dissolved in $100 \mathrm{ml}$ of $0.01 \mathrm{M} \mathrm{HCl}$ and stirred while it was being heated on a hot plate. The mixture (i.e. of cassava starch and $\mathrm{HCl}$ ) was heated to varying temperatures ranging from $65^{\circ} \mathrm{C}-85^{\circ} \mathrm{C}$, after which Borax was added at varying mass (concentrations) ranging from $8 \%-20 \%$ mass of Borax/mass of Starch while stirring until it became sticky. The product (adhesive) was then allowed to cool and qualitative analysis was carried out on it.

Production of adhesive using $\mathrm{NaOH}$ as a gelatinization modifier: $6 \mathrm{~g}$ of dry cassava starch was dissolved in $100 \mathrm{ml}$ of varying concentrations of $\mathrm{NaOH}$ (ranging from $0.01-0.05 \mathrm{M}$ ) and stirred while it was being heated to a known temperature (which is the optimum temperature $85^{\circ} \mathrm{C}$ gotten from experiment 1) using a hot plate. Varying concentrations of Borax were then added to the mixture (i.e. of cassava starch and $\mathrm{NaOH}$ ) at varying mass (ranging from $8 \%$ $20 \%$ mass of Borax/mass of starch), until the mixture was sticky. The product (adhesive) was then allowed to cool and qualitative analysis was carried out on it.

\subsection{Determination of Optimum Conditions for Carrying Out Adhesive Production and Optimization Process}

To determine the optimum process conditions for the production of the adhesive, firstly, the process was carried out at a constant concentration of gelatinization modifier $(\mathrm{HCl})$ while varying mass \% borax/starch and temperature so as to determine the optimum temperature for the production (i.e. using Minitab software), after which using the determined optimum temperature, the concentration of the second gelatinization modifier $(\mathrm{NaOH})$ was varied alongside the $\%$ mass borax/starch so as to determine the best gelatinization modifier. The quality parameters, namely: density, bond strength, viscosity, and $\mathrm{pH}$ of the best quality adhesive were discussed. 


\subsection{Determination of Properties of Adhesives}

The physico-chemical properties of the adhesives were determined using the standardized procedures. The viscosity of the starch adhesive was determined using an NDJ-5S digital rotary viscometer. The density was measured using the ASTM method D1875, which involves using a density cup. The $\mathrm{pH}$ was determined using a $\mathrm{pH}$ meter (Jenco model no. 6173). While the bond strength was determined using a Thwing-Albert QC-3A Universal testing machine according to the ASTM D 1876, commonly called the T-peel test.

\section{Results and Discussion}

The results of the study on the effects of varying process parameters such as processing temperature, concentration of borax, concentration of gelatinization modifier on the quality of the adhesive (such as viscosity, density, $\mathrm{pH}$, bond strength) are presented and discussed.

\subsection{Effect of Temperature and Concentration of Viscosity Enhancer (Borax) on Properties of the Adhesives}

The effects of varying temperature and Concentration of viscosity enhancer (Borax) on the viscosity, density, $\mathrm{pH}$ and bond strength of the adhesives are shown in Figures 1-4 respectively (Table 1).

\section{Viscosity}

As observed in Figure 1: Interaction plot of Viscosity (Factors: Temperature, Mass \% borax/starch), the viscosity of a starch based liquid increases with temperature increase until the starch attains gelatinization temperature, after which a decline is observed [5]. This increase in viscosity is due to the swelling of the starch granules as the reaction temperature is increased [6]. This trend is observed in which as temperature is increased, the viscosity of the adhesive also increases.

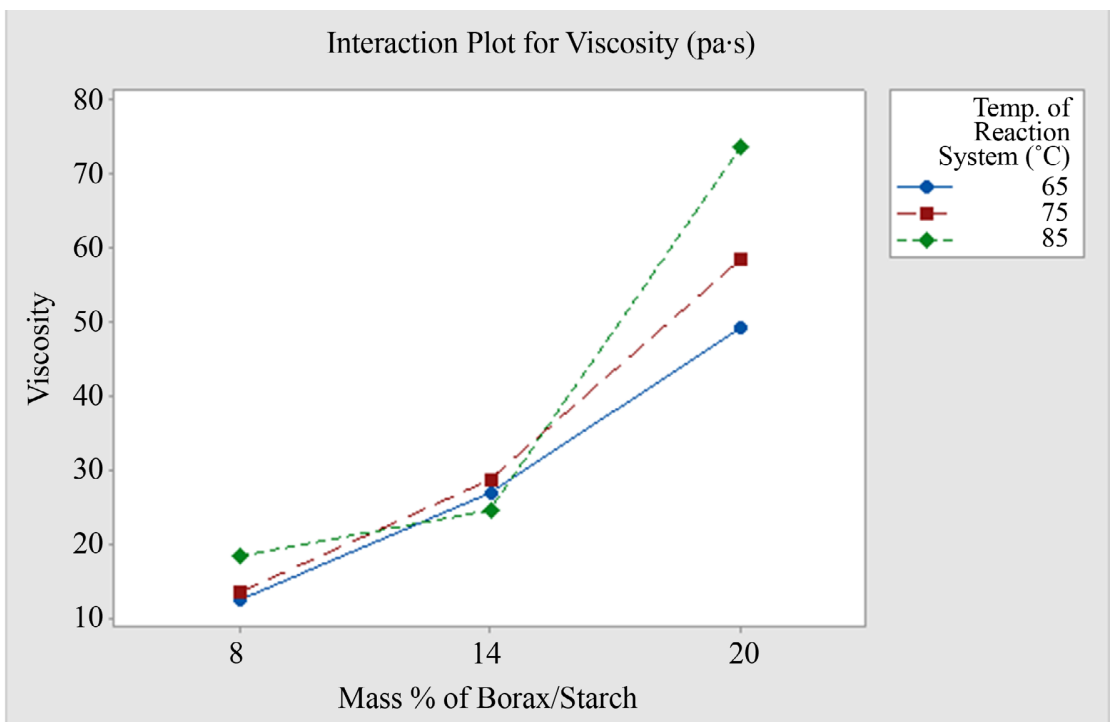

Figure 1. Interaction plot of viscosity (Factors: Temperature, Mass \% borax/starch). 


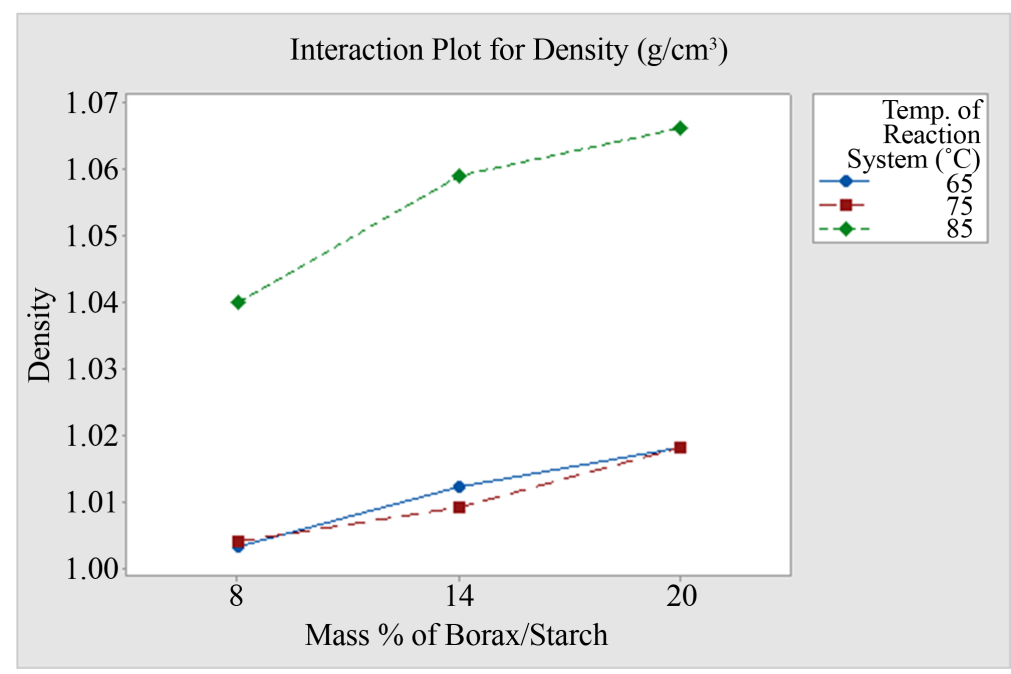

Figure 2. Interaction plot of density (Factors: Temperature, Mass \% borax/starch).

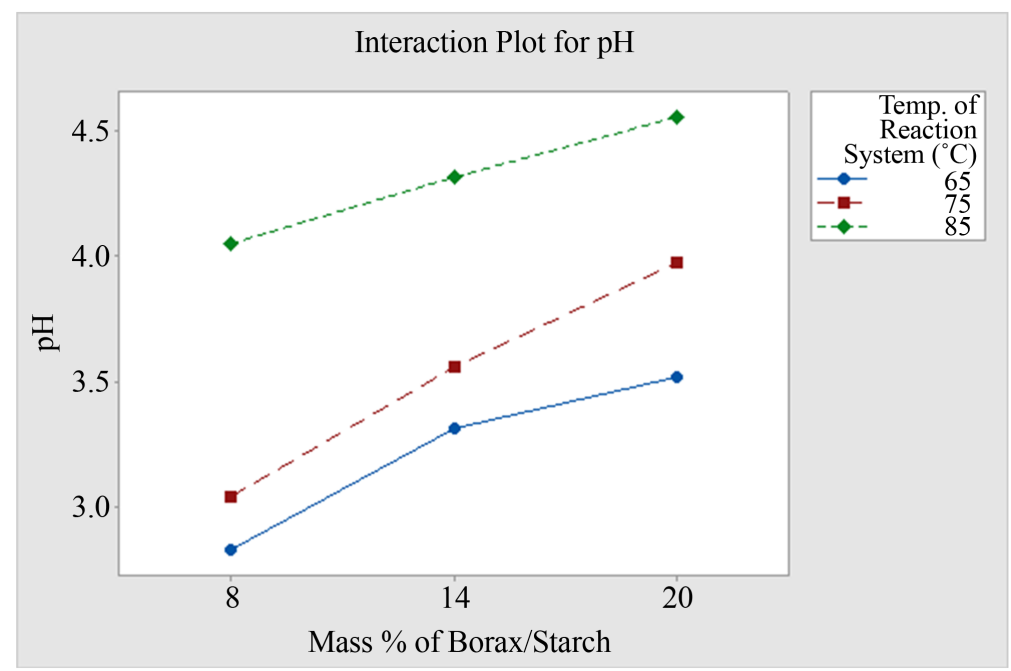

Figure 3. Interaction plot of $\mathrm{pH}$ (Factors: Temperature, Mass \% borax/starch).

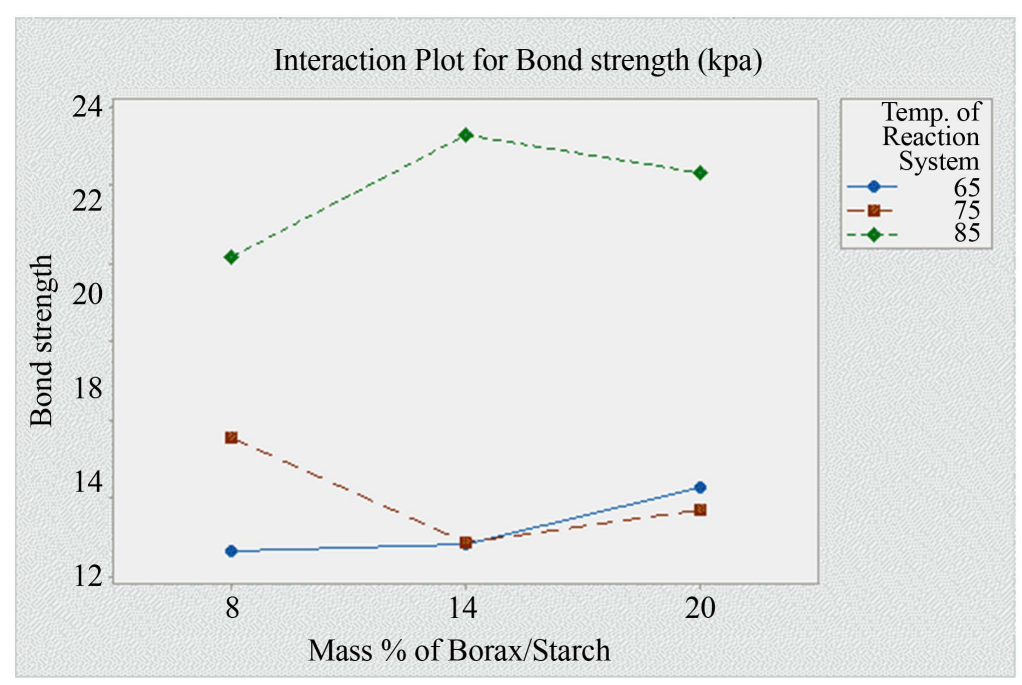

Figure 4. Interaction plot of bond strength (Factors: Temperature, Mass \% borax/starch). 
Table 1. Results of the adhesive properties while varying Temperature and Mass \% bo$\operatorname{rax} /$ starch using $\mathrm{HCl}$.

\begin{tabular}{|c|c|c|c|c|c|c|}
\hline $\mathrm{S} / \mathrm{N}$ & $\begin{array}{l}\text { Temp. of } \\
\text { Reaction } \\
\text { System } \\
\left({ }^{\circ} \mathrm{C}\right)\end{array}$ & $\begin{array}{c}\text { Mass \% of } \\
\text { Borax/Starch }\end{array}$ & $\begin{array}{c}\text { Viscosity } \\
(\mathrm{Pa} \cdot \mathrm{s})\end{array}$ & $\mathrm{pH}$ & $\begin{array}{l}\text { Density } \\
\left(\mathrm{g} / \mathrm{cm}^{3}\right)\end{array}$ & $\begin{array}{c}\text { Bond } \\
\text { strength } \\
(\mathrm{kPa})\end{array}$ \\
\hline 1 & 65 & 8 & 12.47 & 2.82 & 1.003 & 12.61 \\
\hline 2 & 85 & 8 & 18.36 & 4.05 & 1.040 & 20.18 \\
\hline 3 & 65 & 20 & 49.17 & 3.51 & 1.018 & 14.24 \\
\hline 4 & 85 & 20 & 73.44 & 4.55 & 1.066 & 22.31 \\
\hline 5 & 75 & 14 & 28.63 & 3.56 & 1.009 & 12.83 \\
\hline 6 & 65 & 14 & 26.82 & 3.31 & 1.012 & 12.81 \\
\hline 7 & 85 & 14 & 24.56 & 4.31 & 1.059 & 23.27 \\
\hline 8 & 75 & 8 & 13.40 & 3.04 & 1.004 & 15.53 \\
\hline 9 & 75 & 20 & 58.36 & 3.97 & 1.018 & 13.68 \\
\hline 10 & 65 & 8 & 12.46 & 2.84 & 1.003 & 12.60 \\
\hline 11 & 85 & 8 & 18.33 & 4.05 & 1.040 & 20.17 \\
\hline 12 & 65 & 20 & 49.18 & 3.52 & 1.018 & 14.24 \\
\hline 13 & 85 & 20 & 73.44 & 4.55 & 1.066 & 22.31 \\
\hline 14 & 75 & 14 & 28.60 & 3.56 & 1.009 & 12.83 \\
\hline 15 & 65 & 14 & 26.80 & 3.32 & 1.012 & 12.81 \\
\hline 16 & 85 & 14 & 24.56 & 4.31 & 1.059 & 23.27 \\
\hline 17 & 75 & 8 & 13.38 & 3.04 & 1.004 & 15.51 \\
\hline 18 & 75 & 20 & 58.36 & 3.98 & 1.018 & 13.70 \\
\hline
\end{tabular}

Meanwhile, since borax is a viscosity enhancer, addition of more of it to the adhesive would increase its viscosity. Borax forms complexes with starch molecules which are negatively charged, and they further crosslink to form higher molecular weight starch complexes causing a large increase in viscosity [7]. This trend is observed in which as the concentration of borax/starch is increased, the viscosity of the adhesive also increases. A similar result was observed in the work of Jackson [3].

\section{Density}

As shown in Figure 2: Interaction plot of Density (Factors: Temperature, Mass \% borax/starch), the density of the adhesive decreases with temperature because of the swelling of the starch granules, which cause an increase in the adhesive volume. However, when gelatinization temperature is reached and the starch granules swell to their maximum capacity and disintegrate [8], the excess 
moisture which is yet to be absorbed is evaporated, resulting in a drop in volume, and a corresponding increase in density. This explains the decrease in/constant density of adhesive between $65^{\circ} \mathrm{C}$ and $75^{\circ} \mathrm{C}$ and the increase at $85^{\circ} \mathrm{C}$.

Normally, borax has the ability to increase the density of the adhesive. Borax forms complexes with starch molecules which are negatively charged, and they further crosslink to form higher molecular weight starch complexes [7]. So as the concentration of borax is increased the molecular weight of the starch complexes also increases, causing an increase in density. This trend was observed at all temperatures.

\section{$\mathrm{pH}$}

The $\mathrm{pH}$ of the starch adhesive would increase towards alkalinity as noticed in Figure 3: Interaction plot of $\mathrm{pH}$ (Factors: Temperature, Mass \% borax/starch) because as the temperature is increased the unreacted gelatinization modifier is gradually evaporated, leaving behind the dissolved starch and borax which are more basic. This results in a $\mathrm{pH}$ which tends towards basicity with temperature increase.

Basically, borax is a salt with a $\mathrm{pH}$ of about 9. It has a neutralizing effect on the starch adhesive which is made from an acidic gelatinization modifier. This is why the $\mathrm{pH}$ of the starch adhesive tended towards basicity with an increase in the concentration of the viscosity enhancer (borax) from $8 \%-20 \%$.

\section{Bond Strength}

The bond strength of the starch adhesive starts increasing just before reaching gelatinization temperature as seen in Figure 4: Interaction plot of Bond strength (Factors: Temperature, Mass \% borax/starch) because of the gelatinization of the starch, after which there is a decline as a result of a completion of gelatinization [9]. This trend is followed in which there is an increase in bond strength with temperature.

As borax is increased, there is an increase in viscosity, which in turn leads to an increase in bond strength. Borax has an effect of increasing tackiness [10]. Therefore, an increase in the concentration of Borax would in effect cause an increase in the bond strength of the starch adhesive. This trend was observed in the samples prepared at $65^{\circ} \mathrm{C}$ and partially in the samples prepared at $85^{\circ} \mathrm{C}$. The samples prepared at $75^{\circ} \mathrm{C}$ however were problematic. The fluctuations observed at $75^{\circ} \mathrm{C}$ and $85^{\circ} \mathrm{C}$ might be due to errors during testing.

\subsection{Optimization}

From the first set of experiments, the data obtained as responses (i.e. viscosity, density, $\mathrm{pH}$, drying time, bond strength) were used to optimize the factors (i.e. temperature, and mass \% borax/starch) used to obtain these responses using a statistical tool (Minitab). The optimized factors were then used to carry out the second set of experiments. As shown in the diagram Figure 5: Optimization Plot, the optimized factors are a temperature of $85^{\circ} \mathrm{C}$ and 20 mass \% bo$\mathrm{rax} / \mathrm{starch}$. 


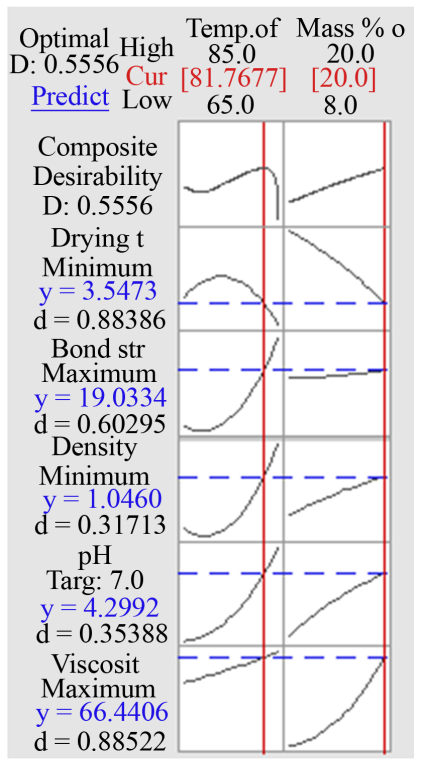

Figure 5. Optimization plot.

\subsection{Effects of Varying Concentration of Gelatinization Modifier on the Properties of the Adhesives}

The effect of varying the concentration of the gelatinization modifier $(\mathrm{NaOH})$ and mass \% borax/starch on the response viscosity, density, $\mathrm{pH}$, bond strength are shown in Figures 6-9 respectively (Table 2).

\section{Viscosity}

The viscosity of the starch adhesive increases with increasing concentration of $\mathrm{NaOH}$ as observed in Figure 6: Interaction plot of Viscosity (Factors: Concentration of $\mathrm{NaOH}$, Mass \% borax/starch). This is due to the fact that increasing the concentration of $\mathrm{NaOH}$ of the starch adhesive causes swelling which in turn causes an increment in viscosity [11]. This trend is observed between the 0.01 and $0.05 \mathrm{M} \mathrm{NaOH}$ solutions. Though, this wasn't in $0.03 \mathrm{M}$ solution probably due to errors with the $0.03 \mathrm{M}$ solutions.

\section{Density}

The density of the starch adhesive was observed to decrease with increases in the concentration of $\mathrm{NaOH}$ as seen in Figure 7: Interaction plot of Density (Factors: Concentration of $\mathrm{NaOH}$, Mass \% borax/starch). This is due to the swelling effect of $\mathrm{NaOH}[11]$ on the adhesive which causes its volume to increase with an increment of the concentration of $\mathrm{NaOH}$. Since density is mass per unit volume, and the mass remains constant while the volume is increasing, which explains the decrease in density with an increase in the concentration of $\mathrm{NaOH}$.

\section{$\mathrm{pH}$}

The $\mathrm{pH}$ of the starch adhesive increases towards basicity as the concentration of $\mathrm{NaOH}$ is increased as shown in Figure 8: Interaction plot of $\mathrm{pH}$ (Factors: Concentration of $\mathrm{NaOH}$, Mass \% borax/starch) since $\mathrm{pH}$ is the negative logarithm of $\mathrm{H}^{+}$concentration [12], and the higher the concentration of $\mathrm{OH}^{-}$the lower the concentration of $\mathrm{H}^{+}$(since as $\mathrm{OH}^{-}$concentration increases, $\mathrm{H}^{+}$ 


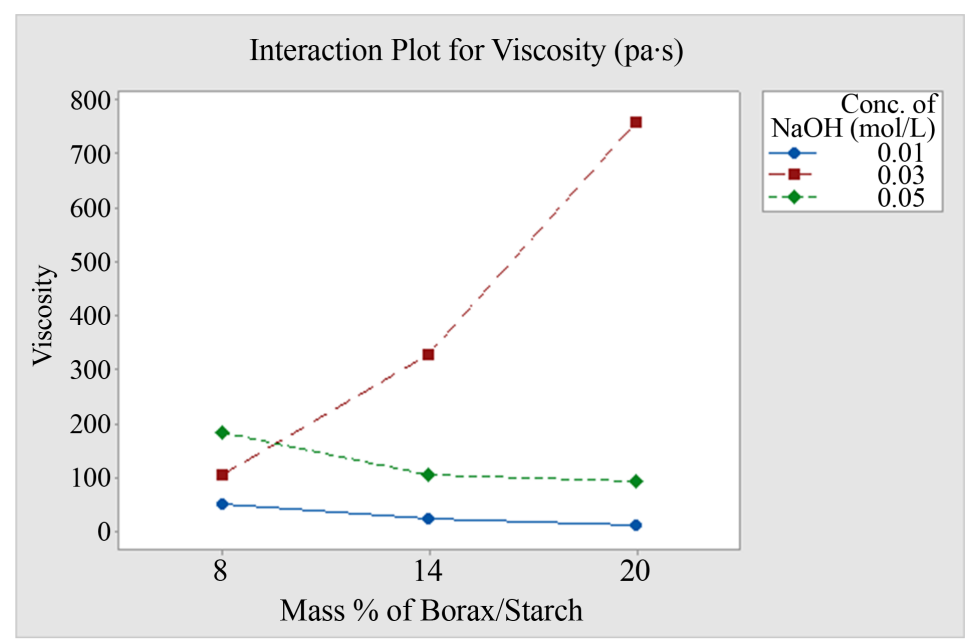

Figure 6. Interaction plot of viscosity (Factors: Concentration of $\mathrm{NaOH}$, Mass \% bo$\operatorname{rax} /$ starch).



Figure 7. Interaction plot of density (Factors: Concentration of $\mathrm{NaOH}$, Mass \% bo$\operatorname{rax} /$ starch).



Figure 8. Interaction plot of $\mathrm{pH}$ (Factors: Concentration of $\mathrm{NaOH}$, Mass \% borax/starch). 


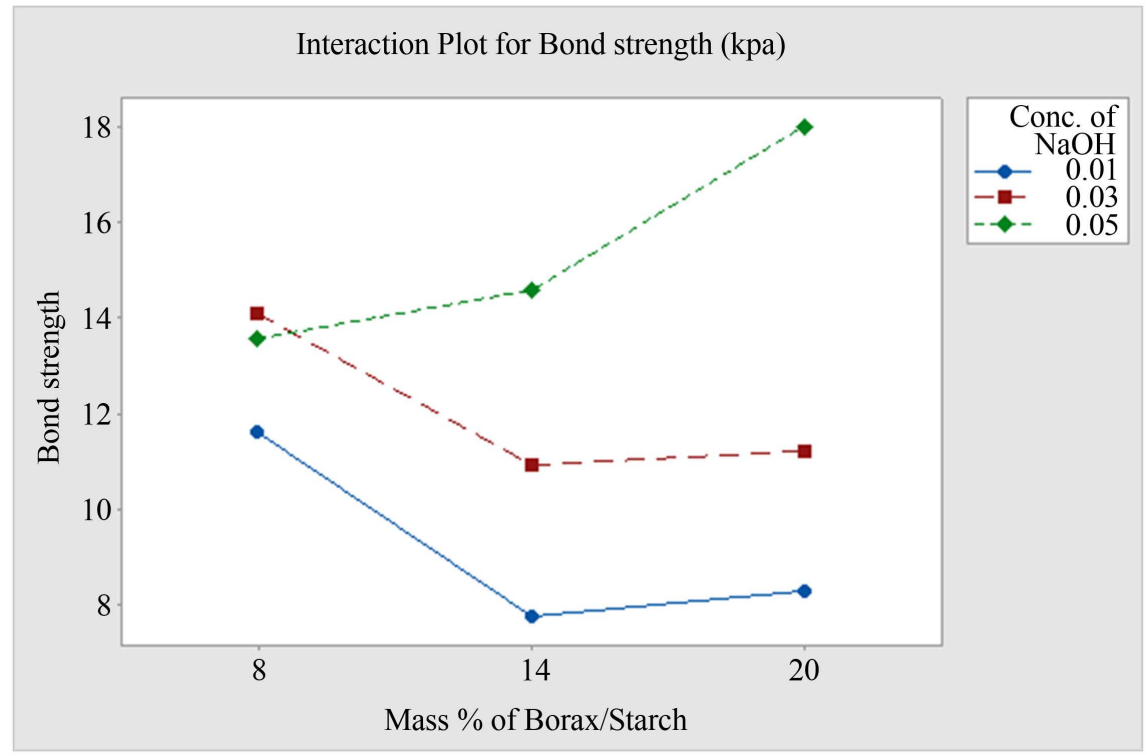

Figure 9. Interaction plot of bond strength (Factors: Concentration of $\mathrm{NaOH}$, Mass \% borax/starch).

Table 2. Results of the adhesive properties while varying the concentration and mass $\%$ borax/starch using $\mathrm{NaOH}$.

\begin{tabular}{|c|c|c|c|c|c|c|}
\hline $\mathrm{S} / \mathrm{N}$ & $\begin{array}{c}\text { Conc. of } \\
\mathrm{NaOH}(\mathrm{mol} / \mathrm{L})\end{array}$ & $\begin{array}{c}\text { Mass \% of } \\
\text { Borax/Starch }\end{array}$ & $\begin{array}{c}\text { Viscosity } \\
(\mathrm{Pa} \cdot \mathrm{s})\end{array}$ & $\mathrm{pH}$ & $\begin{array}{l}\text { Density } \\
\left(\mathrm{g} / \mathrm{cm}^{3}\right)\end{array}$ & $\begin{array}{l}\text { Bond strength } \\
\qquad(\mathrm{kPa})\end{array}$ \\
\hline 1 & 0.01 & 8 & 48.61 & 8.28 & 1.052 & 11.60 \\
\hline 2 & 0.05 & 8 & 182.76 & 9.74 & 1.015 & 13.57 \\
\hline 3 & 0.01 & 20 & 10.26 & 8.73 & 1.156 & 8.30 \\
\hline 4 & 0.05 & 20 & 92.86 & 9.43 & 1.132 & 18.00 \\
\hline 5 & 0.01 & 14 & 23.14 & 8.59 & 1.136 & 7.75 \\
\hline 6 & 0.05 & 14 & 104.40 & 9.47 & 1.097 & 14.60 \\
\hline 7 & 0.03 & 8 & 104.30 & 9.87 & 1.136 & 14.10 \\
\hline 8 & 0.03 & 20 & 757.10 & 9.65 & 1.017 & 11.23 \\
\hline 9 & 0.03 & 14 & 327.78 & 9.80 & 1.016 & 10.91 \\
\hline 10 & 0.01 & 8 & 48.61 & 8.28 & 1.052 & 11.60 \\
\hline 11 & 0.05 & 8 & 182.76 & 9.74 & 1.015 & 13.57 \\
\hline 12 & 0.01 & 20 & 10.26 & 8.73 & 1.156 & 8.30 \\
\hline 13 & 0.05 & 20 & 92.86 & 9.43 & 1.132 & 18.01 \\
\hline 14 & 0.01 & 14 & 23.14 & 8.60 & 1.136 & 7.76 \\
\hline 15 & 0.05 & 14 & 104.40 & 9.47 & 1.097 & 14.60 \\
\hline 16 & 0.03 & 8 & 104.30 & 9.87 & 1.136 & 14.10 \\
\hline 17 & 0.03 & 20 & 757.10 & 9.64 & 1.017 & 11.23 \\
\hline 18 & 0.03 & 14 & 327.78 & 9.80 & 1.016 & 10.91 \\
\hline
\end{tabular}


concentration decreases making the value of the -Log greater). This is explained by the fact that the higher the concentration of a base in a solution, the higher it causes the $\mathrm{pH}$ of the solution it reacts with to be. The $\mathrm{pH}$ tended towards a value of 10 on the $\mathrm{pH}$ scale.

\section{Bond Strength}

The bond strength of the starch adhesive increased with higher concentrations of $\mathrm{NaOH}$ as observed in Figure 9: Interaction plot of Bond strength (Factors: Concentration of $\mathrm{NaOH}$, Mass \% borax/starch). This is attributable to the demonstrated direct correlation between $\mathrm{NAOH}$ concentration and adhesive tackiness [10]. Tackiness is the ability of an adhesive to glue two or more surfaces together, and the stronger they are held together, the higher the bond strength. Therefore, a higher tack means higher bond strength. This explains why an increase in the $\mathrm{NaOH}$ concentration of a starch adhesive increases the bond strength of the adhesive. This trend is observed in the experiments carried out on bond strength.

\section{Preferred Choice of Starch-based Adhesive}

Based on the data from the first set of experiments, using $\mathrm{HCl}$ of $0.01 \mathrm{M}$, the optimum process conditions are a temperature of $85^{\circ} \mathrm{C}$ and $20 \%$ mass of bo$\mathrm{rax} / \mathrm{starch}$. The value of the various properties of the adhesives produced such as viscosity, density, $\mathrm{pH}$ and bond strength are $73.44,1.066,4.55$, and 22.31 respectively. However, for the second set of experiments, varying $\mathrm{NaOH}$ concentration and mass \% borax/starch, the optimum process condition using $0.01 \mathrm{M} \mathrm{NaOH}$ to produce the adhesive at a temperature of $85^{\circ} \mathrm{C}$ was $8 \%$ mass borax/starch. The values of the various properties of the adhesives produced such as viscosity, density, $\mathrm{pH}$ and bond strength were $48.61,1.052,8.28$, and 11.60 respectively.

Comparing the adhesives produced using $\mathrm{HCl}$ and $\mathrm{NaOH}$, it was established that the adhesive produced with $\mathrm{HCl}$ was of a higher quality as characterized by a higher viscosity value, superior density, a desirable $\mathrm{pH}$ value between 4.0 and 7.5, and a much higher bond strength (which is one of the most important properties of adhesives).

\section{Conclusions}

Cassava starch-based adhesives were produced using different processing variables such as type of modifier, mass \% borax/starch and reaction temperature. The various process variables had different impacts on the physico-chemical properties (responses) of the adhesives produced, viz: viscosity, $\mathrm{pH}$, density, bond strength of the product. The effects of the process variables have been analyzed in the discussion of results. Based on the scope of the experiments carried out, the optimum temperature for the production of adhesives was $85^{\circ} \mathrm{C}$, and the best adhesive produced under this condition was synthesized using $\mathrm{HCl}$ rather than $\mathrm{NaOH}$ as the gelatinization modifier with a bond strength (which is the most important quality assessment parameter for adhesives) of $22.31 \mathrm{kPa}$ compared to $\mathrm{NaOH}$ with a bond strength of $11.60 \mathrm{kPa}$. 
It is however recommended that further studies be undertaken to explore the requirements for extending the shelf life of starch based-adhesives since they are prone to early deterioration, compared to adhesives synthesized from inorganic and other mineral-based sources.

\section{Acknowledgements}

The author gratefully acknowledges Covenant University, Nigeria, for the use of her Chemical and Petroleum Engineering Department's Laboratory facilities.

\section{Conflicts of Interest}

The author declares no conflicts of interest regarding the publication of this paper.

\section{References}

[1] Grace, M.R. (1977) Cassava Processing: Cassava Starch and Its Uses. Plant Production and Protection Series. FAO.

[2] Srichuwong, S. and Jane, J.-L. (2007) Physico-Chemical Properties of Starch Affected by Molecular Composition and Structure: A Review. Journal of Food Science and Biotechnology, 16, 663-674.

[3] Akpa, J.G. (2012) Production of Cassava Starch-Based Adhesive. Research Journal in Engineering and Applied Sciences, 1, 219-214,

[4] IITA (2005) Cassava Utilization: Strach Production. Integrated Cassava Project. http://www.cassavabiz.org/postharvest/starch03.htm

[5] Wheatley, C.C., Zakhia, N. and Chuzel, G. (2003) Cassava/The Nature of the Tuber. Encyclopedia of Food Sciences and Nutrition. 2nd Edition, Academic Press, Massachusetts, 964-969. https://doi.org/10.1016/B0-12-227055-X/00181-4

[6] Finnie, S. and Atwell, W.A. (2016) Composition of Commercial Flour. Wheat Flour Handbook, 2nd Edition, Cereals \& Grains Associations, AACC International, Inc., 35-41.

[7] Chattopadhyay, A.K. (2014) Adhesive and Sealant Industry. https://www.adhesivesmag.com/articles/93226-boring-boron-and-adhesives

[8] BeMiller, J.N. and Yongfeng, A. (2019) Starches: Molecular and Granular Structures and Properties. Carbohydrate Chemistry for Food Scientists, 3rd Edition, AACI and Elsevier Inc., 159-182. https://doi.org/10.1016/B978-0-12-812069-9.00006-6

[9] Marino, R., Giovando, S. and Gabriele, D. (2014) Effect of Tannin Addition on the Rheological Properties of Starch-Based Adhesives. Applied Rheology, 24, 46138.

[10] Nasiri, A., Wearing, J. and Dube, M.A. (2020) Using Lignin to Modify Starch-Based Adhesive Performance. Chemengineering, 4, 3. https://doi.org/10.3390/chemengineering 4010003

[11] Roberts, S.A and Cameron, R.E. (2002) The Effects of Concentration and Sodium Hydroxide on the Rheological Properties of Potato Starch Gelatinisation. Carbohydrate Polymers, 50, 133-143. https://doi.org/10.1016/S0144-8617(02)00007-3

[12] Gratrix, A.P. and Enright, S.M. (2006) Foundations of Anesthesia: Basic Sciences for Clinical Practice. Hemmings, Jr, H.C. and Hopkins, P.M., Eds. Elsevier, Philadelphia. 